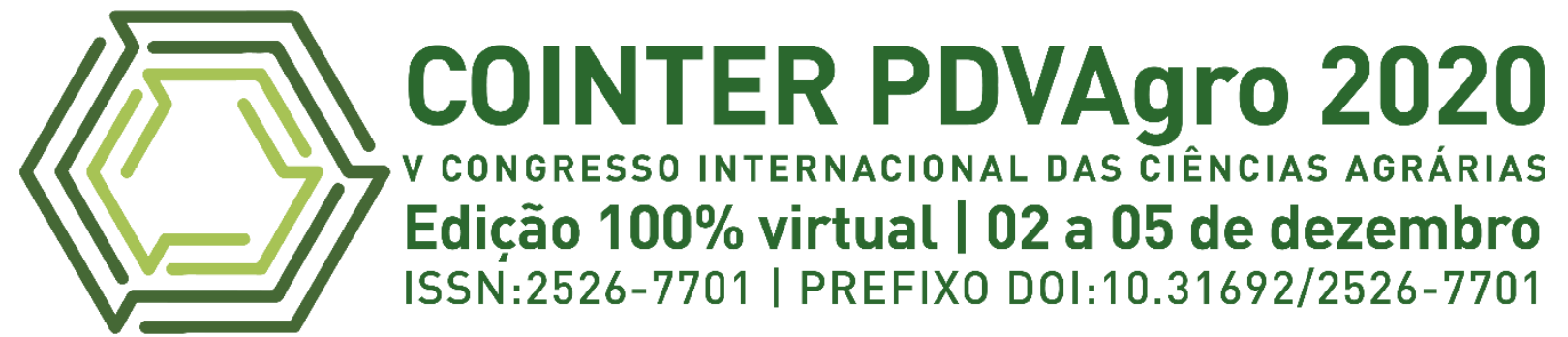

\title{
CARACTERIZAÇÃO DE DIFERENTES VARIEDADES DE ACEROLA (MALPIGHIA EMARGINATA $D C$.) COMERCIALIZADAS EM PETROLINA-PE
}

\section{CARACTERIZACIÓN DE DIFERENTES VARIEDADES DE ACEROLA (MALPIGHIA EMARGINATA DC.) COMERCIALIZADO EN PETROLINA-PE}

\section{CHARACTERIZATION OF DIFFERENT VARIETIES OF ACEROLA (MALPIGHIA EMARGINATA DC.) MARKETED IN PETROLINA-PE}

\author{
Apresentação: Comunicação Oral
}

Mirian de Sousa e Silva ${ }^{1}$; Iasmim Pereira Oliveira ${ }^{2}$; Nailton de Macedo Albuquerque Junior ${ }^{3}$; Silvana Bélem de Oliveira Vilar ${ }^{4}$; Auriana Coelho Barros ${ }^{5}$

DOI: https://doi.org/10.31692/2526-7701.VCOINTERPDVAgro.0509

\begin{abstract}
RESUMO
O cultivo da acerola tem sido crescente no Brasil, devido ao seu considerável valor nutricional e potencial econômico, o fruto da acerola é conhecido por apresentar uso já consolidado para industrialização uma vez que é consumido sob forma de sucos, utilizado no enriquecimento de produtos alimentícios e na forma nutracêuticos. O presente trabalho teve como objetivo avaliar através de análises físicas e físico-químicas, três variedades das acerolas comercializadas na região do Submédio do Vale do São Francisco, Junko, Flor Branca e Costa Rica, em dois estádios de maturação verde e maduro. Foram avaliados: peso, comprimento, diâmetro, densidade, sólidos solúveis, acidez titulável, relação SS/AT, $\mathrm{pH}$ e teor de vitamina C. Os resultados das análises realizadas nos frutos foram tratadas estatísticamente através do programa BioEstat 5.0, sendo submetidos a análise descritiva e anova. Podese observar através dos resultados que todos os cultivares em sua maturação verde se destacou apresentando um maior teor de vitamina $\mathrm{C}$ se comparada com a as maduras. A variedade Junko apresentou um melhor resultado se comparada com as outras variedades, pois apresentou uma maior média na maioria das variantes estudadas, nos dois estádios de maturação, o que a torna um cultivar indispensável para processamentos nas indústrias.
\end{abstract}

Palavra-chave: Processamento, Qualidade, Vitamina C.

1 Tecnóloga em alimentos, IF sertão PE, miriansousanet@hotmail.com

2 Tecnóloga em alimentos, IF sertão PE, mimuefs@gmail.com

3 Tecnólogo em alimentos, IF sertão PE, junior.nailton99@gmail.com

4 Tecnóloga em alimentos, IF sertão PE, silvana.belem@ifsertao-pe.edu.br

5 Tecnóloga em alimentos, IF sertão PE, aurianna.coelho@ifsertao-pe.edu.br

\section{RESUMEN}

El cultivo de la acerola ha ido creciendo en el Brasil, debido a su considerable valor nutritivo y potencial económico, se sabe que el fruto de la acerola ya ha consolidado su uso para la industrialización, ya que se consume en forma de jugos, se utiliza en el enriquecimiento de productos alimenticios y en la forma nutracéutica. Este trabajo tenía por objeto evaluar mediante análisis físicos y químicos, tres variedades de acerola comercializadas en el Submédio do Vale do São Francisco, Junko, Flor Branca y Costa Rica, en dos etapas de maduración verde y madura. Se evaluó el peso, la longitud, el diámetro, la densidad, los sólidos solubles, la acidez valorable, la relación SS/AT, el pH y el contenido de vitamina C. Los 
resultados de los análisis realizados en los frutos fueron tratados estadísticamente a través del programa BioEstat 5.0, siendo sometidos a análisis descriptivos y anova. Se puede observar a través de los resultados que todos los cultivares en su maduración verde se destacaron presentando un mayor contenido de vitamina $\mathrm{C}$ en comparación con los maduros. La variedad Junko presentó un mejor resultado si se la compara con las demás variedades, porque presentó un promedio más alto en la mayoría de las variantes estudiadas, en ambas etapas de madurez, lo que la convierte en un cultivar indispensable para la elaboración en las industrias.

Palabras clave: Procesamiento, Calidad, Vitamina C

\section{ABSTRACT}

The cultivation of acerola has been growing in Brazil, due to its considerable nutritional value and economic potential, the acerola fruit is known to have already consolidated use for industrialization since it is consumed in the form of juices, used in the enrichment of food products and in the nutraceutical form. The present work aimed to evaluate through physical and chemical analyses, three varieties of acerola commercialized in the Submédio region of the San Francisco Valley, Junko, Flor Branca and Costa Rica, in two stages of green and mature maturation. The following were evaluated: weight, length, diameter, density, soluble solids, titratable acidity, SS/AT ratio, $\mathrm{pH}$ and vitamin $\mathrm{C}$ content. The results of the analyses performed on the fruits were treated statistically through the BioEstat 5.0 program, being submitted to descriptive and anova analysis . It can be observed through the results that all the cultivars in their green maturation stood out presenting a higher content of vitamin $\mathrm{C}$ if compared with the mature ones. The Junko variety presented a better result if compared with the other varieties, because it presented a higher average in the majority of the studied variants, in both stages of maturation, which makes it an indispensable cultivar for processing in industries.

Keyword: Processing, Quality, Vitamin C.

\section{INTRODUÇÃO}

Além da grande variedade de espécies produzidas em diferentes regiões e climas do país, a fruticultura brasileira está cada vez mais em expansão. A modernização da agricultura e a forma de exposição e industrialização tornaram as frutas foco do agronegócio nacional.(ANUÁRIO BRASILEIRO DA FRUTICULTUTRA, 2015).

Nos últimos anos o cultivo de acerola obteve um forte crescimento no Brasil, distribuindo-se nas regiões Nordeste, Norte, Sul e Sudeste (RITZINGER; RITZINGER, 2004), a produtividade média nas plantações brasileiras é de 60,966 t/há/ano. Seu plantio é considerado como de elevada sobrevivência a seca e pouca resistência ao frio, sendo assim, se espalhou por várias áreas tropicais, subtropicais e até semiáridas. O Nordeste, por suas condições de solo e clima, é a principal região produtora representando cerca de $78 \%$ da produção nacional, entre os estados nordestinos que cultivam o plantio de acerola, destaca-se Pernambuco, responsável por $35 \%$ da safra anual (IBGE, 2017).

Além da importância para a alimentação, as frutas também impactam a sociedade e a economia. Em termos de economia, o Brasil produz aproximadamente 45 milhões de toneladas de frutas tropicais por ano, ocupando o terceiro lugar entre os maiores produtores mundiais (Gorayeb, 2019). A região Nordeste é um forte contribuinte para essa alta produtividade, por isso tem o clima, solo, preço da terra atraente, mão de obra disponível e localização superior de 
exportação de aliados, por isso se destaca em comparação às outras regiões (Rocha, 2013; Neris, 2018).

A acerola (Malpighia emarginata DC.), é uma fruta produzida na América do Sul e Central e cresce em climas tropicais e subtropicais (LEFFA et al., 2014). Os frutos têm geralmente 1 a 4 cm de diâmetro e pesam entre 2 a 15 gramas (DELVA; SCHNEIDER, 2013a; NUNES et al., 2011), e possuem colorações verdes durante o desenvolvimento e, à medida que amadurecem, adquirem pigmentos alaranjados e não se tornam vermelhos escuros até a maturidade total e torno de 5 dias (BARBOZA; TAVARES; MELO, 1996). Além disso, apresentam alta atividade metabólica pós-colheita, o que os torna muito perecíveis, principalmente quando vendidos in natura (DELVA; SCHNEIDER, 2013a; NUNES et al., 2011).

A demanda do mercado para o consumo de fibra longa aumentou significativamente recentemente, devido às informações sobre os compostos presentes nas frutas e seus componentes biologicamente ativos. Sua alta concentração de vitamina C é o principal atrativo econômico e hoje é utilizada na produção de conservantes naturais e alimentos nutritivos. Essas características aumentam a aplicabilidade dos compostos bioativos da fruta, aumentando seu valor comercial (POLETTO, 2019).

A conservação pós-colheita deste fruto deve considerar o armazenamento refrigerado para reduzir a atividade metabólica e prolongar o prazo de validade e comercialização da fruta in natura. Sabe-se que a qualidade física e físico-química dos frutos também pode variar de acordo com os procedimentos de colheita e pós-colheita, com a presença de ferimentos, com o tamanho do fruto, o grau de maturação e outros.

As diversas formas de comercialização podem variar de acordo com o mercado e as exigências do consumidor. Considerando os diversos fatores peculiares a esta fruta, o objetivo deste trabalho foi avaliar três genótipos de aceroleira, cultivadas no submédio do vale do São Francisco nos seus estádios de maturação.

\section{FUNDAMENTAÇÃO TEÓRICA}

\section{PRODUÇÃO DE FRUTAS}

O Brasil possui uma ampla variedade de frutas dispostas em todas as localidades. A adaptação sua ampla dimensão territorial e sua inclusão, particularmente nas zonas de clima tropical e temperado, é o país com a maior biodiversidade em relação às frutas, pouco modificada e, em razão disso são utilizados no mercado (MATIETTO et al. 2010; PEREIRA et 


\section{CARACTERIZAÇÃO DE DIFERENTES VARIEDADES DE ACEROLA}

al., 2013). Numa escala mundial, o Brasil se encontra em $3^{\circ}$ lugar no ranking de produção de frutas, por apresentar uma grande diversidade tanto de frutas frescas como processadas (ALAMAR et al., 2016), com aproximadamente 45 milhões de toneladas por ano, dos quais $65 \%$ são vendidos no mercado interno e 35\% no mercado externo (EMBRAPA, 2019). Dados da ABRAFRUTAS (2020), mostram que a produção de frutas atingiu um nível de crescimento de $16 \%$ nas exportações de frutas no ano de 2019, onde 980.000 toneladas foram exportadas, em comparação com 848.000 toneladas em 2018.

Conforme a Confederação da Agricultura e Pecuária do Brasil (CNA, 2016) esse setor gera um grande valor econômico para o país, assim como, oportunidades de empregos direto e indireto para pequenos e grandes produtores.

A fruticultura no Brasil equivale a $5 \%$ da produtividade mundial, onde, em torno de $53 \%$ é atribuída ao processo industrial de frutas e $47 \%$ ao comércio de frutas frescas (SOUSA et al., 2011).

O Instituto Brasileiro de Geografia e Estatística (IBGE, 2016), estimou que a produção frutífera em 2017 atingisse 44 milhões de toneladas, superando a produção estimada do ano anterior, 2016 que foi de 43,8 milhões de toneladas, tais dados só comprovam o quanto como o mercado apresenta-se forte.

\section{ACEROLA}

O Brasil é um dos poucos países que cultivam comercialmente acerola, que foi introduzida no Estado de Pernambuco no ano de 1955 por meio de sementes oriundas de Porto Rico, trazidas pela professora Maria Celene Cardoso de Almeida, da Universidade Federal Rural de Pernambuco, de onde se espalhou para o Nordeste e para outras regiões do País, com limitação para região Sul por suas temperaturas extremamente baixa (LOPES; PAIVA, 2002, RITZINGER; RITZINGER, 2011).

Segundo o censo agropecuário apresentado pelo IBGE (2017), estima-se que o Brasil tem uma área plantada de, aproximadamente, 5.753 hectares, de aceroleira, com uma produtividade média de 60.966 toneladas de frutas por ano, onde o Nordeste participa de $78 \%$ desse total, com uma área em torno de 4.042 hectares plantada com acerola. Os principais estados produtores são Pernambuco, que representa $(35,02 \%)$ da produção nacional, seguido pelo Ceará (12,43\%), Sergipe (8,90\%), e Paraíba (8,08\%). Petrolina e Juazeiro considerados polos da região do submédio do São Francisco ocupam o primeiro lugar no ranking dos municípios de Pernambuco e Bahia produtores de acerola, juntos produzem em média 16.347 toneladas do fruto por ano. 
Em Petrolina-PE o cultivo de acerola tem despertado o interesse comercial, especialmente dos pequenos produtores, que apresentam uma área plantada próxima a 62 hectares. As condições climáticas da região, aliadas à irrigação possibilitam que a planta produza praticamente o ano todo (CODEVASF, 2016).

A demanda do mercado pelo consumo de acerola aumentou significativamente nos últimos anos. Isso se dá ao fato de um maior conhecimento da presença de compostos como carotenoides, compostos fenólicos, alta atividade antioxidante e uma fonte rica em vitamina $\mathrm{C}$ (ácido ascórbico) (REZENDE et al., 2017).

\section{VARIEDADES COMERCIAIS DA ACEROLEIRA NO SUBMÉDIO DO VALE DO SÃO FRANCISCO}

A acerola apresenta grande variabilidade genética com diferenças marcantes no tamanho do fruto, coloração da casca e da polpa, composição físico-química, suculência, textura, aroma e sabor (RITZINGER; SOARES FILHO, OLIVEIRA, 2003).

As cultivares de aceroleira são, sobretudo, "variedades monoclonais", desenvolvidas a partir da seleção, clonagem e avaliação de plantas individuais. Em geral, são plantas que exibem características fenotípicas distintas em áreas de cultivo comercial ou experimental e, assim, são coletadas e passam a ser propagadas vegetativamente em maior escala. Atualmente, as principais variedades cultivadas no Submédio do Vale do São Francisco são: Junko, Flor Branca, BRS Sertaneja, Costa Rica, Okinawa e BRS Cabocla (SOUZA; DEON; CASTRO et al., 2013).

Segundos dados apresentados pela empresa Plantec (Planejamento e Engenharia Agronômica Ltda.) as principais variedades cultivadas no Perímetro de Irrigação Senador Nilo Coelho são: Sertaneja, Okinawa, Flor Branca, Costa Rica, comum e Junko.

\section{Junko}

A cultivar Junko desenvolvida por uma empresa da região do Submédio do Vale do São Francisco, apresenta planta robusta de porte médio, tem copa mediamente volumosa, de coloração verde médio e flores rosadas. Seus frutos são de tamanho médio, coloração púrpura, com cascas levemente irregular, apresentando saliências e depressões longitudinais. A polpa é bem firme e relativamente resistente a danos mecânicos que ocorrem durante o manuseio e transporte. Os frutos denotam boa conservação pós-colheita, permanecendo com aspecto comercial por mais de 15 dias sob armazenamento a $12^{\circ} \mathrm{C}$. O sabor é bastante ácido decorrente ao alto teor de acido ascórbico, em média, superior a $2.500 \mathrm{mg} / 100 \mathrm{~g}$ nos frutos maduros, sendo, 


\section{CARACTERIZAÇÃO DE DIFERENTES VARIEDADES DE ACEROLA}

que no estádio verde, esse valor é bem maior, o que faz esse cultivar uma ótima opção para o mercado industrial. Outra característica que a diferencia de outras variedades é sua permanência na planta por vários dias após seu amadurecimento, o que facilita a colheita e reduz as perdas causadas pelo contato dos frutos com o solo. (SOUSA et al., 2013).

\section{Flor Branca}

Esse genótipo, Flor branca é proveniente de seleção genética realizada no Estado do Pará e difundida pela Niquisa, empresa do grupo Nichirei. Uma planta de menor porte, com ramos dispersos, copa compacta e arejada, bastante sensível a estresses abióticos, como déficit hídrico, salinidade e carência nutricional, de maneira que suas folhas rapidamente adquirem coloração amareladas nessas condições. Suas flores são brancas e sob irrigação, a floração é abundante, podendo produzir flores durante o ano inteiro, de modo que, entre as cultivares plantadas no Submédio do Vale do São Francisco, é a que apresenta maior regularidade de produção. Apresenta frutos pequenos em torno de $5 \mathrm{~g}$ com coloração vermelha, quando maduros. A consistência da polpa é muito delicada, causando rápida deformação dos frutos, liberando seu conteúdo aquoso. Por esse motivo, são muito suscetíveis a danos durante o manuseio e o transporte e têm uma curta conservação pós-colheita, assim, os frutos devem ser colhidos preferencialmente, durante o estádio inicial de maturação, ou seja, frutos verdes e sua produção sejam destinados ás indústrias. Apresentam teor de vitamina $\mathrm{C}$ em aproximadamente 1,500 mg/100g nos frutos maduros. (SOUZA et al., 2013; FIGUEIREDO NETO et al., 2014).

\section{Costa Rica}

Embora seja bastante cultivada no Submédio do Vale do São Francisco a origem do genótipo Costa Rica é desconhecida, esta cultivar apresenta planta de porte alto, ramos dispersos e copa arejada. As folhas são grandes, de coloração verde médio e as flores são róseas. Os frutos são de tamanho médio, formato cônico e quando imaturos, apresentam coloração verde com manchas amarronzadas, característica que a diferencia das demais cultivares. Quando maduros, os frutos tornam-se completamente vermelhos. A polpa é medianamente consistente, com sabor e aroma agradáveis e peculiares, devido seu alto valor de sólidos solúveis e seu baixa teor de acidez apresentando uma média superior a $1.500 \mathrm{mg} / 100 \mathrm{~g}$ de polpa de acido ascórbico. (SOUZA et al., 2013).

\section{METODOLOGIA}

Foram avaliados frutos de acerola das variedade Junko, Flor Branca e Costa Rica, nos 
estádios de maturação verde e maduro. As análises dos frutos foram realizadas no IF sertão-PE, no período de setembro a novembro de 2016. As etapas do trabalho seguiram a ordem apresentada a seguir.

\section{Coleta dos frutos}

Os frutos foram transportados e acondicionados em basquetas de plástico tipo PEAD de $20 \mathrm{Kg}$, foram colocados na balança, pesado, separado por variedades e identificado com etiquetas de cores diferentes especifica, em saquinho plástico, foram coletados em média $500 \mathrm{~g}$ de acerola de cada variedade e maturação.

\section{Seleção}

Dentro de cada variedade e maturação tomou-se ao acaso 30 frutos para caracterização física.

Figura 1. Três cultivares de acerola em duas maturações distinta verde e madura.

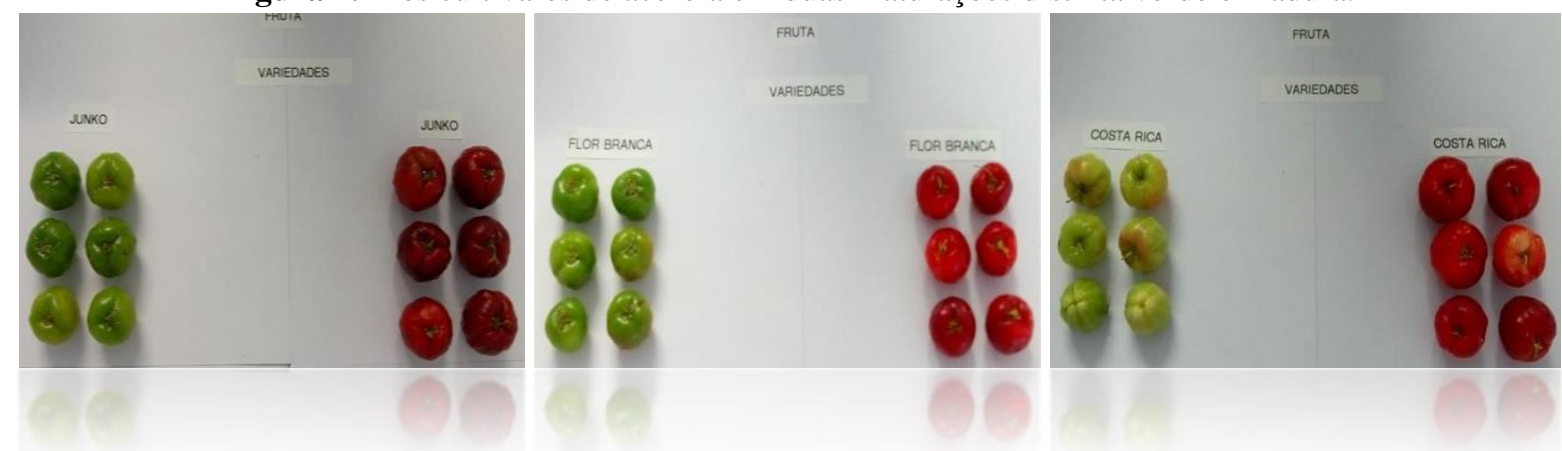

Fonte: Própria (2016).

\section{ANÁLISES FÍSICAS}

Peso

Determinou-se, pesando em média 30 frutos individualmente em balanças semianalítica (METTLER TOLEDO), com precisão de 0,01g.

\section{Diâmetros e Comprimento}

Por meio do paquímetro foi realizada a medição direta de cada fruto e expressa em milímetros.

\section{Densidade}




\section{CARACTERIZAÇÃO DE DIFERENTES VARIEDADES DE ACEROLA}

Em laboratório os frutos são pesados em uma caixa de volume conhecido com base em suas medidas internas, comprimento, largura e altura que simula a caixa dos produtores.

\section{Extração do suco}

Para determinação das características físico-químicas, os frutos foram macerados e filtrados. A partir, do filtrado foi realizado as seguintes análises

\section{ANÁLISES FISÍCO-QUÍMICAS}

\section{Teor de Sólidos Solúveis $(\mathrm{S} / \mathrm{S})$}

Foram determinados por meio de um refratômetro digital de bancada (ATAGO Smart1) e os resultados expressos em ${ }^{\circ}$ Brix.

\section{Acidez Titulável (A/T)}

Foram determinadas a partir da titulação de $1 \mathrm{~g}$ da amostra com hidróxido de sódio $(0,1 \mathrm{~N})$, utilizando fenolftaleína como indicador do ponto de viragem (IAL, 2008), os resultados foram obtidos em porcentagem em acido málico:

\section{Potencial Hidrogênico (pH)}

$\mathrm{O}$ pH foi medido através de um potenciômetro digital (Mettler DL 12), previamente calibrado com soluções tampões de pH 7.0 e 4.0.

\section{Relação SS/AT}

A relação SS/AT foi obtida através da razão entre os valores de sólidos solúveis e da acidez titulável.

\section{Teor de Vitamina $\mathrm{C}$}

Foi obtido por titulometria com solução de iodato de potássio $(0,01 \mathrm{~N})$ de acordo com a metodologia proposta pelo Instituto Adolfo Lutz (2008), sendo os dados expressos em mg/100g de polpa.

\section{Análise estatística}

Os dados encontrados foram submetidos à análise descritiva, utilizando o programa BioEstat 5.0, calculando as médias das características avaliadas e seus respectivos desvio 
padrão e coeficiente de variação, assim como, a análise de variância onde as medias foram submetidas ao teste de Tukey ao nível de 5\% de probabilidade.

\section{RESULTADOS E DISCUSSÃO}

Analisando as Tabela 1 e 2 observam-se os valores médios das características físicas das três variedades de acerola. Essas determinações físicas mostram um aumento nos valores de peso, comprimento e diâmetro durante a evolução do processo de amadurecimento das três cultivares.

Tabela 1. Características físicas de variedades de acerola no estádio de maturação do fruto verde.

\begin{tabular}{ccccc}
\hline ATRIBUTOS & GENOTIPOS & MÉDIA & DP & CV (\%) \\
\hline \multirow{2}{*}{ Peso $(\mathbf{g})$} & Junko & $5.7974 \mathrm{a}$ & 1.0054 & 17.35 \\
& Flor Branca & $3.6217 \mathrm{c}$ & 0.3814 & 10.53 \\
& Costa Rica & $4.2810 \mathrm{~b}$ & 0.4769 & 10.78 \\
\hline \multirow{2}{*}{ Comprimento $(\mathbf{m m})$} & Junko & $19,77 \mathrm{a}$ & 1.1063 & 5.60 \\
& Flor Branca & $16.58 \mathrm{~b}$ & 0.7850 & 4.74 \\
& Costa Rica & $19.14 \mathrm{a}$ & 0.7969 & 4.16 \\
\hline \multirow{2}{*}{ Diâmetro $(\mathbf{m m})$} & Junko & $22.27 \mathrm{a}$ & 1.6326 & 7.73 \\
& Flor Branca & $19.67 \mathrm{c}$ & 0.9405 & 4.87 \\
& Costa Rica & $20.76 \mathrm{~b}$ & 1.1575 & 5.58 \\
\hline \multirow{2}{*}{ Densidade $\left(\mathbf{g} / \mathbf{m}^{\mathbf{3}}\right)$} & Junko & $0.49 \mathrm{~b}$ & 0.0240 & 4.99 \\
& Flor Branca & $0.50 \mathrm{a}$ & 0.0174 & 3.49 \\
& Costa Rica & $0.49 \mathrm{~b}$ & 0.0150 & 2.92
\end{tabular}

Fonte: Própria (2016).

Os pesos médios obtido pela variedade Flor Branca no fruto maduro apresentaram valores menores comparados com o fruto verde, o que não ocorre nas outras variedades, isso se deve a pequenas deficiências de nutrientes que afetam na produtividade das aceroleiras e consequentemente no tamanho do fruto, esse é um dos genótipos que apresentam maior produção durante todo o ano. 
CARACTERIZAÇÃO DE DIFERENTES VARIEDADES DE ACEROLA

Tabela 2. Características físicas de variedades de acerola no estádio do fruto maduro.

\begin{tabular}{ccccc}
\hline ATRIBUTOS & GENOTIPOS & MÉDIA & DP & CV (\%) \\
\hline \multirow{2}{*}{ Peso $(\mathbf{g})$} & Junko & $9.3217 \mathrm{a}$ & 1.1936 & 12.81 \\
& Flor Branca & $3.2865 \mathrm{c}$ & 0.5385 & 16.38 \\
& Costa Rica & $6.4838 \mathrm{~b}$ & 0.8877 & 13.69 \\
\hline \multirow{2}{*}{ Comprimento $(\mathbf{m m})$} & Junko & $26.54 \mathrm{a}$ & 1.6835 & 6.34 \\
& Flor Branca & $17.23 \mathrm{c}$ & 0.9259 & 5.37 \\
& Costa Rica & $20.00 \mathrm{~b}$ & 1.2152 & 5.86 \\
\hline \multirow{2}{*}{ Diâmetro $(\mathbf{m m})$} & Junko & $23.36 \mathrm{a}$ & 1.7167 & 7.28 \\
& Flor Branca & $18.60 \mathrm{~b}$ & 1.0218 & 5.50 \\
& Costa Rica & $23.38 \mathrm{a}$ & 1.5506 & 6.60 \\
\hline \multirow{2}{*}{ Densidade $\left(\mathbf{g} / \mathbf{m}^{3}\right)$} & Junko & $0.50 \mathrm{~b}$ & 0.0285 & 5.76 \\
& Flor Branca & $0.51 \mathrm{a}$ & 0.0193 & 3.77 \\
& Costa Rica & $0.50 \mathrm{~b}$ & 0.0270 & 5.27
\end{tabular}

Fonte: Própria, 2016.

As três cultivares apresentaram resultados satisfatórios nos parâmetros analisados, pois estão de acordo com Mendes et al. (2012), que relata que o peso da acerola de um modo geral varia de 3 a 16g, e Estevam et al. (2018) ao estudar variedades de acerola, nos dois estádios de maturação, encontraram valores inferiores (massa fresca, comprimento e diâmetro) aos do presente estudo, uma vez que estes valores podem variar de região para região, de acordo com solo, clima entre outros fatores.

Calculando a densidade aparente da acerola conhecemos a quantidade de frutos a ser acomodada em embalagem especifica, evitando assim danos mecânicos na colheita, transporte e varejo dos frutos, a variedade Flor Branca apresentou uma maior densidade, resultado esse compatível, pois, esse genótipo possui peso menor e formato que facilita acomodar mais frutos sem deixar espaços entre eles, a mesma situação não ocorre com as outras variedades, por apresentarem um maior tamanho e formato irregular, o que não permite os frutos se encaixarem deixando assim espaços entre eles.

Observando os resultados da Tabela 3, o maior teor de vitamina C 3949mg/100g foi encontrado na variedade Junko que esta relacionada proporcionalmente ao alto nível de acidez 1.76\%. As variedades Costa Rica e Flor Branca apresentaram resultados similares para ácido ascórbico e para acidez titulável, respectivamente. 
Tabela 3. Características físico-químicas de variedades de acerola no estádio verde.

\begin{tabular}{|c|c|c|c|c|}
\hline ATRIBUTOS & GENOTIPOS & MÉDIA & DP & $\mathrm{CV}(\%)$ \\
\hline \multirow{3}{*}{ Sólidos Solúveis ( ${ }^{\circ}$ Brix) } & Junko & $7.49 \mathrm{a}$ & 0.4312 & 5.76 \\
\hline & Flor Branca & $7.19 \mathrm{~b}$ & 0.3414 & 4.88 \\
\hline & Costa Rica & $7.72 \mathrm{a}$ & 0.0806 & 5.72 \\
\hline \multirow{3}{*}{$\begin{array}{c}\text { Acidez Titulável (\% em ácido } \\
\text { málico) }\end{array}$} & Junko & $1.76 \mathrm{a}$ & 1.1111 & 6.30 \\
\hline & Flor Branca & $1.44 \mathrm{~b}$ & 0.0646 & 4.50 \\
\hline & Costa Rica & $1.41 \mathrm{~b}$ & 0.1399 & 9.94 \\
\hline \multirow{3}{*}{ Potencial Hidrogênico (pH) } & Junko & $3.34 \mathrm{~b}$ & 0.1237 & 3.70 \\
\hline & Flor Branca & $3.31 \mathrm{~b}$ & 0.9390 & 2.84 \\
\hline & Costa Rica & $3.39 \mathrm{a}$ & 0.1765 & 5.20 \\
\hline \multirow{3}{*}{ SS/AT } & Junko & $4.25 \mathrm{c}$ & 0.0240 & 4.99 \\
\hline & Flor Branca & $4.99 \mathrm{~b}$ & 0.0174 & 3.49 \\
\hline & Costa Rica & $5.47 \mathrm{a}$ & 0.0150 & 2.92 \\
\hline \multirow{3}{*}{ Vitamina C (mg/100g de polpa) } & Junko & $3.949 \mathrm{a}$ & 0.2700 & 6.83 \\
\hline & Flor Branca & $3.002 \mathrm{~b}$ & 0.2239 & 7.49 \\
\hline & Costa Rica & $2.986 \mathrm{~b}$ & 0.3099 & 10.39 \\
\hline
\end{tabular}

Fonte: Própria (2016).

França (2016) estudou 37 clones de aceroleira e verificou que os teores de ácido ascórbico variaram de 1376 a 3125 mg/100g em frutos verdes. Santos (2016) avaliando o cultivar junko em Petrolina-PE, encontrou uma média de $3.585 \mathrm{mg} / 100 \mathrm{~g}$ de acido ascórbico para a mesmo estádio de maturação, um teor de $1.87 \%$ de acido málico e $\mathrm{pH} 3.27$, valores esses bem próximos com o presente trabalho.

Maciel et al. (2010) afirmam que o teor de vitamina $\mathrm{C}$ na acerola pode ser influenciado por vários fatores como a localização geográfica, práticas de cultivo, regime pluvial, exposição à luz do sol, características genéticas e, principalmente, o estádio de maturação em que os frutos se encontram, com maiores teores de vitamina $\mathrm{C}$ nos frutos verdes.

Segundo Ferreira (2013) a determinação da acidez titulável fornece dados importantes na apreciação do estado de conservação de um fruto. A acidez no fruto é dada pela presença de ácidos orgânicos variados como o ácido cítrico, ácido ascórbico (Vitamina C) e compostos fenólicos. Entretanto, quando um produto apresenta dados de acidez total tituláveis e pH baixos pode-se perceber que ele possua maiores teores de compostos fenólicos ou ácido cítrico (VIEIRA, 2010). 


\section{CARACTERIZAÇÃO DE DIFERENTES VARIEDADES DE ACEROLA}

Tabela 4. Características físico-químicas de variedades de acerola no estádio maduro.

\begin{tabular}{ccccc}
\hline ATRIBUTOS & GENOTIPOS & MÉDIA & DP & CV (\%) \\
\hline \multirow{2}{*}{ Sólidos Solúveis ( ${ }^{\circ}$ Brix) } & Junko & $7.74 \mathrm{~b}$ & 0.5028 & 6.30 \\
& Flor Branca & $7.79 \mathrm{~b}$ & 0.6564 & 8.42 \\
& Costa Rica & $8.91 \mathrm{a}$ & 0.5238 & 5.88 \\
\hline \multirow{2}{*}{ Acidez Titulável (\% em ácido málico) } & Junko & $1.78 \mathrm{a}$ & 0.1501 & 9.53 \\
& Flor Branca & $1.20 \mathrm{~b}$ & 0.0884 & 7.37 \\
& Costa Rica & $1.14 \mathrm{~b}$ & 0.1083 & 9.54 \\
\hline \multirow{2}{*}{ Potencial Hidrogênico $(\mathbf{p H})$} & Junko & $3.24 \mathrm{~b}$ & 0.1153 & 3.56 \\
& Flor Branca & $3.32 \mathrm{a}$ & 0.1275 & 3.84 \\
\hline SS/AT & Costa Rica & $3.34 \mathrm{a}$ & 0.0880 & 2.63 \\
\hline Vitamina C (mg/100g de polpa) & Junko & $5.08 \mathrm{c}$ & 0.0240 & 4.99 \\
& Flor Branca & $6.49 \mathrm{~b}$ & 0.0174 & 3.49 \\
& Costa Rica & $7.81 \mathrm{a}$ & 0.0150 & 2.92 \\
\hline & Junko & $2.306 \mathrm{a}$ & 0.2595 & 11.26 \\
\hline
\end{tabular}

Fonte: Própria (2016).

Analisando as cultivares de acerola madura pode-se observar que as três variedades apresentam uma média maior para o teor de sólidos solúveis comparando com a maturação verde (Tabela 4), o mesmo não ocorre com as demais variáveis, essas transformações ocorrem por se tratar de um fruto climatérico, ou seja, passam por uma série de alterações durante o processo de maturação, amadurecimento e senescência, destacando-se o ganho de açúcares, decréscimo na acidez e acentuada perda de vitamina $\mathrm{C}$, essas mudanças podem ocorrer quando o fruto esta na planta ou pós-colheita. (CHITARRA; CHITARRRA, 2005).

A variedade Costa Rica obteve a maior média para sólidos solúveis $\left(8.91^{\circ} \mathrm{Brix}\right)$ e consequentemente uma menor acidez (1.14\%), essa relação (RATIO), entre ambos são os atributos mais importantes para definição de sabor dos frutos, ou seja, quanto maior for a relação SS/AT mais doces serão os frutos, uma forma usual para avaliar o sabor e selecionar a matéria prima para o processamento.

Batista et al. (2015) encontrou resultados muito similares para o mesma variedade em questão, teor de sólidos solúveis, (8.3 Brix) e acidez titulavel (1.1\% de acido málico), o que segundo Ritzinger e Ritzinger (2009), os frutos mais doces são destinados ao consumo in natura e as ácidas para a industrialização. O cultivar Junko apresentou a menor média para a relação SS/AT (5.08), sendo assim classificado como uma variedade ácida, o que corresponde seu alto teor de acido ascórbico $(2.306 \mathrm{mg} / 100 \mathrm{~g})$, ideal para o uso em industrias que já tem uma perda natural durante o processamento, uma vez q a vitamina $\mathrm{C}$ é facilmente degradada na presença de luz e com variação de temperatura (MEZADRI et al., 2008). 
Segundo o IBRAF (1995), o teor de acido ascórbico mínimo aceito pelas indústrias é de $1.200 \mathrm{mg} / 100 \mathrm{~g}$ de polpa, ${ }^{\circ}$ Brix em torno de 7 e 7,5, peso mínimo de $4 \mathrm{~g}$ e mais de $15 \mathrm{~mm}$ de tamanho. Observou-se que todas as variedades presentes nesse estudo atingiram a tais requisitos, apenas a variedade Flor Branca apresentou um peso menor do que o estabelecido, por se tratar de uma variedade mais suscetível a degradação, possivelmente sua colheita foi realizada antes de atingir o ponto ideal de maturação.

\section{CONCLUSÃO}

As três variedades apresentaram resultados satisfatório de acordo com as características físicas e físico- químicas avaliadas, o que as tornam apta para o uso agroindustrial. O cultivar junko se destacou, pois, além de apresentar um alto teor de vitamina $\mathrm{C}$, a polpa é mais firme, o que torna a variedade mais resistente. Já a Flor Branca, apesar de ser mais suscetíveis a danos pós-colheita devido sua fragilidade, tem como vantagem, a produção durante todo o ano. A variedade Costa Rica apresentou resultados intermediários, aparentemente ela é mais próxima fisicamente do cultivar Junko, mas, com relação às variáveis físico-químicas, como acidez titulável e teor de ácido ascórbico, ela não apresentou diferença significativa com a variedade Flor Branca.

\section{REFERÊNCIAS}

ABRAFRUTAS - Associação Brasileira dos Produtores Exportadores de Frutas e Derivados. Dados estatísticos do setor: Estatísticas das exportações de frutas em 2019.

AGRIANUAL: Anuário da agricultura brasileira. São Paulo: FNP Consultoria Comércio, 2010. $520 \mathrm{p}$.

ALAMAR, P. D.; CARAMÊS, E. T. S.; POPPI, R. J.; PALLONE, J. A. L. Quality evaluation of frozen guava and yellow passion fruit pulps by NIR spectroscopy and chemometrics. Food Research International, v. 85, n. 7, p. 209-214, 2016.

ANUÁRIO BRASILEIRO DA FRUTICULTURA. Santa Cruz do Sul: Editora Gazeta Santa Cruz, 1004 p, 2015.

BARBOZA, S. B. S. C.; TAVARES, E. D.; MELO, M. B. de. Instruções para o cultivo da acerola. Aracaju: EMBRAPA-CPATC, 1996. 42p. (EMBRAPA-CPATC. Circular Técnica. 6). BATISTA, P. F.; LIMA, M. A. C. de; TRINDADE, D. C. G. da; ALVES, R. E. Quality of diferente topical fuits cultivars produced in he Lower Basin of the São Fran Valley. Ciência Agronômica, Fortaleza, v. 46, n. 1, p. 176-184, 2015.

CHITARRA, A. B.; CHITARRA, M. I. F. Pós-colheita de frutos e hortaliças: fisiologia e manuseio. 2.ed. Lavras: UFLA, 2005. 
CNA - Confederação da Agricultura e Pecuária do Brasil. Fruticultura: Balanço 2016. Perspectivas 2017. Disponível em: <http://www.cnabrasil.org.br/sites/default/files/sites/default/files/uploads/10_fruticultura.pdf> . Acesso em: 08/07/2020.

DELVA, L.; SCHNEIDER, R. G. Acerola (Malpighia emarginata DC): production, postharvest handling, nutrition, and biological activity. Food Reviews International, v. 29, n. 2, p. 107-126, 2013.

EMPRAPA. Ciência que transforma: Resultados e impactos positivos da pesquisa agropecuária na economia, no meio ambiente e na mesa do brasileiro. 2019. Disponível em: <https://www.embrapa.br/grandes-contribuicoes-para-a-agricultura-brasileira/frutas-ehortalicas > . Acesso em 03/08/2020.

FIGUEIREDO NETO, A. et al. Determinação de vitamina C e avaliação físico-química em três variedades de acerla cultivadas em Petrolina-PE. Nucleus, v.11, n. 1, p.83-92, 2014.

FRANÇA, L. G. Indicação de clones de acerola visando a qualidade de frutos verdes para processamento. Dissertação (mestrado) - Instituto Federal do Ceará, Canpus Limoeiro do Norte, 2016.

FRITAS B. S. M.; Estudo da caracterização e qualidade físicas e químicas do fruto de cajá (Spondias mombin L.), e aproveitamento da polpa. Dissertação Mestrado- Instituto Federal Goiano- Campus Rio Verde, 2017.

GORAYEB, T. C. C., MARTINS, F. H., COSTA, M. V. C. G., JUNIOR, J. G. C., BERTOLIN, D. C., \& DEZANI, A. A. (2019). Estudo das perdas e desperdício de frutas no Brasil. Anais Sintagro, 11(1).

IBGE - INSTITUTO BRASIELEIRO DE GEOGRAFIA E ESTATÍSTICA. Censo Agropecuário,2017.Disponivelem:https://censos.ibge.gov.br/agro/2017/templates/censo_agro /resultadosagro/agricultura.html?localidade $=0 \&$ tema=76215. Acesso em 19/08/2020.

INSTITUTO; A; LUTZ. Métodos físico-químico para análise de alimentos. São Paulo: ANVISA,2008.Disponívelem:<http://www.sidalc.net/cgibin/wxis.exe/?IsisScript=senasa.xis\& method=post \&formato $=2 \&$ cantidad $=1 \&$ expresion $=m f n=000089>$. Acesso em 13/02/2018.

LEFFA, D. D. et al. Corrective effects of acerola (Malpighia emarginata DC.) juice intake on biochemical and genotoxical parameters in mice fed on a high-fat diet. Mutation Research - Fundamental and Molecular Mechanisms of Mutagenesis, v. 770, p. 144-152, 2014.

MACIEL, M. I. S; MELO, E. LIMA, V.; SOUZA, K. A.; SILVA, W. Caracterização físicoquímica de frutos de genótipos de aceroleira (Malpighia emarginata D.C.), Revista Ciência e Tecnologia de Alimentos, Campinas, v.30, n.4, 2010.

MANICA, I. Clima e solo. In: Acerola: Tecnologia de produção, pós-colheita, congelamento, exportação, mercados; editado por Ivo manica. - porto Alegre: Cinco Continentes, 2003, p.45.

MAPA. Instrução Normativa $n^{0}$ 49, de 26 de setembro de 2018. Disponível em: 
https://alimentusconsultoria.com.br/instrucao-normativa-no-49-de-26-de-setembro-de-2018mapa/. Acesso em 05/09/2018.

MATTIETTO, R.A.; LOPES, A.S.; MENEZES, H.C. Caracterização física e físico-química dos frutos da cajazeira (Spondias mombin L.) e de suas polpas obtidas por dois tipos de extrator. Brazilian Journal Food Technology., v. 13, p. 156-164, 2010.

MENDES et al., A cultura da acerola. -3ed. rev.amp..- Brasília, DF: Embrapa, 2012.

NERIS, T. S.; SOUSA, S.; LOSS, R. A.; CARVALHO, J. W. P., \& GUEDES, S. F. (2018). Avaliação físico-química da casca da banana (Musa spp.) in natura e desidratada em diferentes estádios de maturação. Ciência e Sustentabilidade, 4(1), 5-21.

NOGUEIRA, R. J. M. C.; MORAES, J. A. P. V.; BURITY, H. A..; SILVA JUNIOR, J. F. Efeito do estádio de maturação dos frutos nas características físico-químicas de acerola. Pesquisa Agropecuária Brasileira, Brasília, v37, n.4, 2002.

NUNES, E.S.; D’ARAÚJO COUTO, F.A.; BRAZ, V.B. Seleção de genótipos de aceroleira (Malpighia Spp.).In: CONGRESSO BRASILEIRO DE FRUTICULTURA, 17., 2002, Belém, Anais...Belém: SBF, 2002. CD-ROM.

PEREIRA, C.T.M.; SILVA, C.R.P.; LIMA, A.; PEREIRA, D.M.; COSTA, C.N.; NETO, A.A.C. Obtenção, caracterização físico-química e avaliação da capacidade antioxidante in vitro da farinha do resíduo de acerola (Malpighia glabra L.). Acta Tecnológica, v.8, p. 50$56,2013$.

REZENDE, Y. R. R. S.; NOGUEIRA, J. P.; NARAIN, N. Comparison and optimization of conventional and ultrasound assisted extraction for bioactive compounds and antioxidant activity from agro-industrial acerola (Malpighia emarginata DC) residue. LWT - Food Science and Technology, 85, p. 158-169, 2017. Disponível em: <https://doi.org/10.1016/j.lwt.2017.07.020>. Acesso em 10/09/2020.

RITZINGER, R.; RITZINGER, C. H. S. P. Acerola. Informe Agropecuário. Belo Horizonte, v. 32, n. 264, p. 17-25, set./out, 2011.

ROCHA, A. J. A. C.; POLETTO, P.; BORDIGNON, S. E. Avaliação do Potencial Antimicrobiano do Extrato da Acerola. Universidade Federal de Santa Catarina Florianópolis, 2019.

ROCHA, M. S.; FIGUEIREDO; R. W. D.; ARAÚJO, M. A. D. M.; MOREIRA-ARAÚJO, R. S. D. R. (2013). Caracterização físico-química e atividade antioxidante (in vitro) de frutos do cerrado piauiense. Revista Brasileira de Fruticultura, 35(4), 933-941.

SANTOS, R. S. Avaliação físico-química de acerola cv. Junko cultivada em Petrolina- PE. Dissertação Conclusão de Curso - Instituto Federal Pernambucano- Campus Petrolina Zona Rural, 2016.

SEBRAE. Boletim de inteligência agronegócio fruticultura. 2015. Disponível em: <http://www.sebraemercados.com.br/wp-content/uploads/2015/11/Panorama-do-mercado-de-fruticultura-no-Brasil.pdf> . Acesso em: 27/09/2020. 
SOUSA, F.F.; DEON, M.D.; CASTRO, J.M.C.; CALGARO, M.; Contribuição das pesquisas realizadas na Embrapa Semiárido para a cultura da aceroleira. Petrolina-PE. Embrapa Semiárido, 2017.

SOUSA, F.F.; DEON, M.D.; CASTRO, J.M.C.; LIMA, M.A.C.; RYBKA, A.C.P.; FREITAS,S.T. Principais variedades de aceroleiras cultivadas no Submédio do Vale do São Francisco. Petrolina-PE. Embrapa Semiárido, 2013.

SOUSA, M.S.B. e VIEIRA, L.M. Fenólicos totais e capacidade antioxidante in vitro de resíduos de polpas de frutas tropicais. Brazilian Journal of Food Thecnology, v. 14, p. 202$210,2011$.

VIEIRA, A. S. C. Características físico-químicas e composição mineral da polpa de passiflora setacea. 2010. Dissertação - Mestrado em Agronomia, Brasília (DF), 2010. 